\title{
Fiber-Optic Fluoroimmunoassay for Determination of Dermatophagoides farinae Allergen by Flow Analysis Technique
}

\author{
Kumiko Miyajima ${ }^{1,2}$, Daisuke Miki ${ }^{1}$, Takahiro Arakawa², \\ Hiroyuki Kudo ${ }^{3}$, Hirokazu Saito ${ }^{4}$ and Kohji Mitsubayashi'1,2,* \\ ${ }^{1}$ Graduate School of Medical and Dental Sciences, Tokyo Medical and Dental University, \\ 1-5-45 Yushima, Bunkyo-ku, Tokyo 113-8510, Japan \\ ${ }^{2}$ Institute of Biomaterials and Bioengineering, Tokyo Medical and Dental University, \\ 2-3-10 Kanda-Surugadai Chiyoda-ku, Tokyo 101-0062, Japan \\ ${ }^{3}$ School of Science and Technology, Meiji University, \\ 1-1-1 Higashi-Mita, Tama-Ku, Kawasaki-shi, Kanagawa 214-8571, Japan \\ ${ }^{4}$ Department of Mechanical Engineering, Tokyo National College of Technology, \\ 1220-2 Kunugida-machi, Hachioji-shi, Tokyo 193-0997, Japan
}

(Received June 10, 2013; accepted August 21, 2013)

Key words: Dermatophogoides farinae, Der f1, allergen, optical fiber, flow cell

A fiber-optic fluoroimmunoassay system for Dermatophagoides farinae allergen (Der f1) is developed and applied to a flow analysis system. The immunoassay system consists of an optical fiber probe with a collective lens, a reaction cell with inlet/outlet ports for reagents, a laser diode for excitation light source, and a photodiode for detecting fluorescence. The measurement principle is based on sandwich immunoassay. By flowing reagents into the reaction cell, the optical fiber probe becomes coated with immunological complexes formed by capture antibodies, Der $f 1$ derived from house dust mite D. farinae as target analytes, and fluorescent dye (cyanine 5)-labeled antibodies. An excitation light is transmitted into the optical fiber probe, and then the fluorescent molecules of fluorophore-labeled antibodies are excited by the evanescent light of the laser diode. The fluorescence recoupled into the probe is quantified by the photodiode as current values. The calibration range for Der $f 1$ is from 0.98 to $250 \mathrm{ng} / \mathrm{ml}$, and the assays are completed within $16 \mathrm{~min}$. To achieve faster immunoassay, changes in fluorescence signal are monitored using the probe exposed to the fluorescent-labeled antibodies for the detection of Der $f 1$, and calculated to obtain the rate of fluorescence increase for each Der $f 1$ concentration. The calibration range is equal to that of the above-mentioned assay, and the assay time is shortened to $6 \mathrm{~min}$. In the future, the flow immunoassay system allows determining allergens with high precision in a residential environment on site.

*Corresponding author: e-mail: m.bdi@tmd.ac.jp 


\section{Introduction}

Allergic diseases such as bronchial asthma or rhinitis have been serious global health problems in recent years. ${ }^{(1-5)}$ Indoor allergens, which include house dust mites, fungi, cockroaches, pets and others, are known as important risk factors for allergy. ${ }^{(6-12)}$ In particular, dust mite is a major source of inhaled allergens, and they can be found in most homes, usually in beds, pillows, carpets, upholstered furniture, or any other cloth materials. ${ }^{(13)}$ Dermatophagoides farinae is one of the common species of house dust mite in the residential environment and produces an allergen protein, $D$. farinae allergen (Der f1). ${ }^{(14,15)}$ As a treatment measure for patients who have allergic diseases, there are several approaches such as aeroallergen avoidance, medication usage to control symptoms, and immunotherapy in allergy. In developed countries, people spend a lot of time indoors than outdoors; therefore, the avoidance of exposure to indoor allergens is the first step in the treatment of allergies. In addition, by implementing effective environmental management to reduce allergen exposure, quantitative and high-throughput assessment techniques for allergens are needed to understand the correct state of pollution of airborne allergens in the indoor environment.

Several techniques for the detection of Der $f 1$ in the residential environment are already in place, for example, counting mites, which is not a quantitative method of determining the amount of allergen, a semiquantitative colorimetric assay (Acarex Test) to measure guanine, ${ }^{(16)}$ an enzyme-linked immunosorbent assay (ELISA), ${ }^{(17)}$ an electron spin resonance (ESR) radical immune assay, ${ }^{(18)}$ and other immunological assay methods. However, nonquantitative or semiquantitative methods are rapid but lack accuracy, and quantitative immunoassay methods have high sensitivity but are labor-intensive and time consuming for usage in the actual residential environment. Therefore, both highthroughput and high-sensitivity analysis for Der $f 1$ is requred for the treatment and prevention of allergic diseases.

In recent years, fiber-optic biosensors have been widely investigated. These biosensors use some combination of biological receptors and physical or chemical transducers, which represent a new and unique technology, and they show high sensitivity, low sample volume, and fast detection to measure absorbance fluorescence or scattering characteristic. ${ }^{(19-23)}$ A fiber sensing platform based on an evanescent field is of particular interest for chemical and biological sensing.(24-27) The fiber-optic immunosensor in this study uses the fluorescent immunoassay principle. The sensor is used for the measurement of fluorescent light excited by an evanescent wave generated by a laser diode to quantitatively detect biomolecules immobilized on the optical fiber surface.

This study describes a new fiber optic fluorescent immunosensor with a sample flow system for Der $f 1$ detection. Der $f 1$ is derived from $D$. farinae as mentioned earlier, and it is one of the most important indoor allergens. The objective of this study is to implement an immunological assay for allergens, which is faster, more sensitive, and easier than existing methods. 


\section{Materials and Methods}

\subsection{Reagents}

Der $f 1$ derived from $D$. farinae (Der $f 1$ standard, Lot 2761, $2500 \mathrm{ng} / \mathrm{ml}$ ) was purchased from INDOOR Biotechnologies, Inc. (Charlottesville, Virginia). Anti-Der $f 1$ monoclonal antibodies as capture antibodies (Anti-Der $f 1$ mAb 6A8, Lot 2828, 2 $\mathrm{mg} / \mathrm{ml}$ ) and anti-Der $f 1$ monoclonal antibodies as detection antibodies (Anti-Der f1 $\mathrm{mAb} 4 \mathrm{Cl}$, Lot $2469,2 \mathrm{mg} / \mathrm{ml}$ ) were purchased from INDOOR Biotechnologies, Inc. Fluorescent molecules (cyanine 5; Cy5) were used to label to the detection antibodies using a commercial labeling kit (Cy5-Ab labeling kit, PA35000, GE Healthcare UK Ltd. Buckinghamshire, England). Bovine serum albumin (BSA, Lot 401-041, $10 \mathrm{~g}$ ) was purchased from Wako Pure Chemical Industries, Ltd. (Osaka, Japan). All other chemicals were reagent grade. The wash buffer used for the optical fiber probe was 10 $\mathrm{mM}$ phosphate buffer $\mathrm{pH} 7.4$ (PB) + 0.05\% Tween 20 (PBT). The dilution buffer used for the capture antibodies was $80 \mathrm{mM}$ carbonate-bicarbonate buffer, that for BSA was PB, that for Der 11 was PBT, and that for Cy5-labeled antibodies was PBT + 0.1\% BSA.

\subsection{Optical fiber probe preparations}

The optical fiber probes were contributed by Canon Chemicals Inc. The probe is $4 \mathrm{~cm}$ in length and $0.78 \mathrm{~mm}$ in diameter, and made from polystyrene. Prior to the preparation of reagents for the immobilization of capture antibodies, distal ends of 20 $\mu \mathrm{l}$ pipette tips were sealed with thermal bond to produce $100 \mu \mathrm{l}$ containers. The capture antibodies were diluted with carbonate-bicarbonate buffer to a concentration of $10 \mu \mathrm{g} / \mathrm{ml}$, and $100 \mu \mathrm{l}$ antibody solutions were transferred to each container mentioned above. The optical fiber probes were incubated overnight at $4{ }^{\circ} \mathrm{C}$ in antibody solutions. The antiDer $f 1$ antibody-coated probes were then rinsed in PBT and incubated for $1 \mathrm{~h}$ at room temperature in $1 \%$ BSA-PB $(100 \mu \mathrm{l})$ to block the unoccupied parts on the surface of the probe to reduce the amount of nonspecific binding of proteins.

\subsection{Preparation of Cy5-labeled antibody}

The cyanine reagent is known to be useful as a fluorescent label for biological compounds. ${ }^{(28,29)}$ The detection antibodies were labeled with Cy5-bifunctional dye. Antibodies that contained $0.6 \mathrm{mg}$ of proteins were diluted with $1 \mathrm{ml}$ of $\mathrm{PB}$. The antibody solution was added to a coupling buffer ( $1 \mathrm{M}$ sodium carbonate buffer, $\mathrm{pH}$ 9.3) and gently mixed. The entire volume of the solution was transferred to a vial of Cy5 bisfunctional dye and incubated for 30 min with mixing approximately every 10 min at room temperature in the dark. Then, the labeled protein was separated from the unconjugated dye using a gel filtration column. The final dye-to-protein ratio ( $\mathrm{Cy} 5$ molecules per IgG) was calculated on the basis of absorbances of $280 \mathrm{~nm}$ for the protein and $650 \mathrm{~nm}$ for the Cy5 dye. The labeled antibodies were diluted with PBT + 1\% BSA and stored at $4{ }^{\circ} \mathrm{C}$ until used. 


\subsection{Principle of fluorimmunoassay}

The construction and principle of the fluoroimmunoassay system are shown in Fig. 1. Prior to the measurement step, a sandwich format immune complex should form on the probe surface. The probe coated with capture antibodies is first incubated with the antigen Der $f 1$ solutions for $5 \mathrm{~min}$. After the washing step, the probe is incubated with Cy5-labeled antibodies for 5 min to form a sandwich format immune complex. When an excitation light of $650 \mathrm{~nm}$ wavelength from a laser diode is injected into the probe, a socalled evanescent wave field is created near the probe. An evanescent wave is formed at the probe surface if light propagates in an optical fiber probe with an angle greater than the critical angle to create the condition of total internal reflection. Immune complexes with fluorophores bound on the surface of the probe are excited by an evanescent wave. The fluorophore's emission light of $670 \mathrm{~nm}$ wavelength recouples into the probe and is detected by the photodiode as current values. Figure 2 shows the composition of the flow cell system. Der $f 1$ and Cy5-labeled antibody solutions are put in the syringe, and the optical fiber probe coated with capture antibodies is set in the flow cell. To implement the immunoassay procedures such as antigen-antibody reaction, the syringes are controlled to inject and collect the solution.

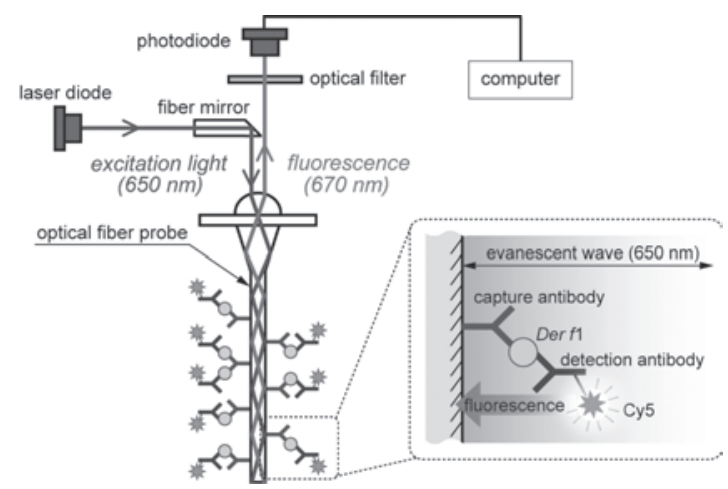

Fig. 1. Principle of fiber optic fluoroimmunoassay. A fluorescence-labeled antigen-antibody complex was made on the fiber surface. The excitation light $(650 \mathrm{~nm}$ laser light) was transmitted into the optical fiber, then the fluorescence dye was excited by an evanescent wave generated on the fiber. The fluorescent light $(670 \mathrm{~nm})$ was detected by a photodiode.

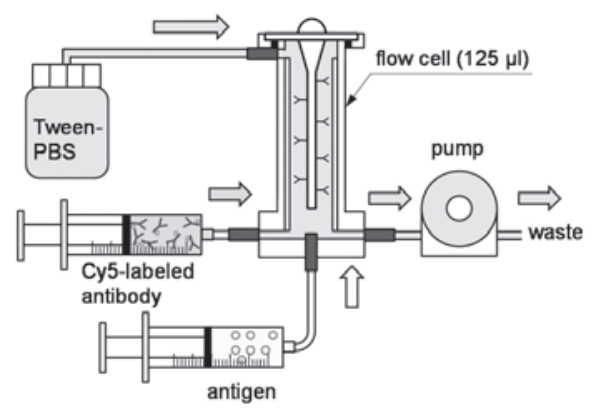

Fig. 2. Design of flow cell system for fluoroimmunoassay. Antigen and labeled antibody solutions are put in syringes, and the solutions are injected or collected depending on each immunological reaction for the assay. 


\subsection{Process of fluoroimmunoassay}

The fluoroimmunoassay was performed via four steps shown in Fig. 3. First, the wash buffer was flowed in the cell and the signal was read as an initial value (step I). Then, the Cy5-labeled antibodies were flowed in the cell and incubated for $5 \mathrm{~min}$, and then the signal was read to confirm the amount of nonspecific binding of detection antibody after removing unbound antibody and rinsing the probe with wash buffer (step II). Next, the Der $f 1$ solution (concentrations of $0.24-250 \mathrm{ng} / \mathrm{ml}$ ) was flowed and incubated for $5 \mathrm{~min}$, and the signal was read after excess sample was removed and the probe was rinsed with wash buffer (step III). Finally, the Cy5-labeled antibody was flowed again and incubated for $5 \mathrm{~min}$. If the Der $\mathrm{f} 1$ antigen is bound to the surface of the probe, the Cy5-labeled antibody will bind to the capture antigen and form a fluorescently labeled immune complex on the surface of the probe. The fluorescence signal was read during the incubation with detection antibody to monitor the antibody binding. After the incubation, the excess detection antibody was removed and the probe was rinsed with wash buffer, and the fluorescence signal was read as the final fluorescence value (step IV).

\section{Results and Discussion}

\subsection{Der f1 measurement using fluoroimmunoassay system}

The changes in fluorescence intensity at each measurement step (I to IX) were detected and shown in Fig. 4. The concentrations of Der f1 solutions were from 0.24 to $250 \mathrm{ng} / \mathrm{ml}$ and each reading time was $20 \mathrm{~s}$. The nonspecific reaction was hardly confirmed at step II, and stable current values at every four steps were obtained. The Der $f 1$ concentration of $250 \mathrm{ng} / \mathrm{ml}$ gave the strongest signal enhancement after the antibody/antigen/labeled-antibody sandwich was formed, and the signal strength decreased depending on the Der $f 1$ concentration. The reaction time in each reaction step was $5 \mathrm{~min}$ and the signal reading time after each reaction was $20 \mathrm{~s}$. Therefore, the measurement using the immunoassay system was completed within 16 min. The
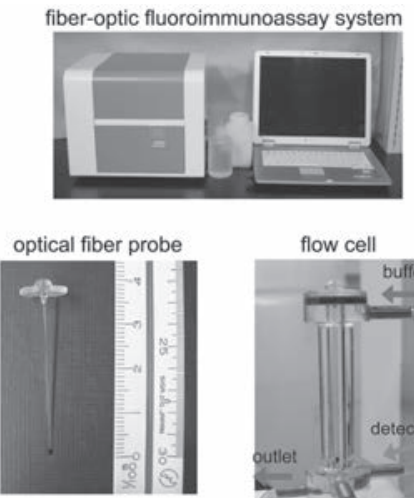

flow cell

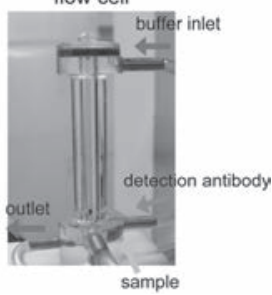

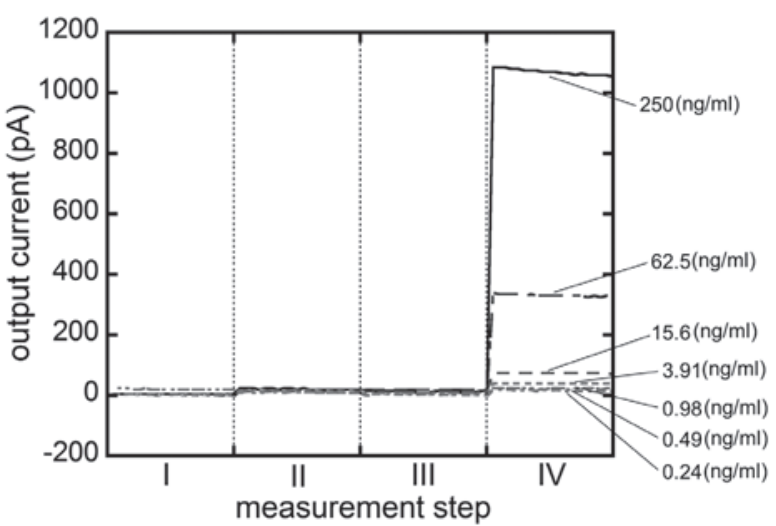

Fig. 3 (left). Process of Der $f 1$ detection by fluoroimmunoassay using flow cell.

Fig. 4 (right). Changes in fluorescence intensity of response to $\operatorname{Der} f 1$ concentrations. The signal of nonspecific reaction was negligibly low at step II (capture antibody and Cy5-labeled antibody reaction), and stable current values at every four measurement steps were obtained immediately. 
immunoassay system was less time-consuming to measure the allergen than existing immunological methods, such as ELISA that needs a long reaction time for each reaction reagent (e.g., samples, detection antibody, and substrate solution).

The calibration curve quantified by the fluoroimmunoassay with a flow measurement system is shown in Fig. 5. Signal differences between steps III and IV were taken as the output value. The figure shows that concentrations of the Der $f 1$ solution were quantified using the flow measurement system with the range of $0.98-250 \mathrm{ng} / \mathrm{ml}$. The coefficient of determination was 0.99 deduced by regression analysis as shown by the following equation:

$$
\text { Output current }(\mathrm{pA})=13.7 \times[\operatorname{Der} \mathrm{f1}(\mathrm{ng} / \mathrm{ml})]^{0.73} \text {. }
$$

The difference in the output value caused by the individual difference in the optical fiber was evaluated by measuring the fluorescent strength 5 times for each concentration. Although the difference was minimal, it was negligibly small for quantifying the Der f1. Thus, Der $f 1$ can be detected with stability using the flow system. On the other hand, the result of colorimetric ELISA for the standard Der $f 1$ solution is also shown in Fig. 5, and the calibration curve is the dashed line in this figure. Details of the ELISA procedure are described in ref. 30. In brief, the detection antibody was labeled with biotin, and streptavidin-peroxidase was conjugated with the sandwich immune complex. The ABTS (2,2'-azinobis [3-ethylbenzothiazoline-6-sulfonic acid]-diammonium salt) substrate was added and then color developed (absorbance at $405 \mathrm{~nm}$ ). The coefficient of determination using ELISA was 0.99, and the calibration curve was shown by the following equation:

$$
\text { Absorbance }=6.74 \times 10^{-3} \times[\operatorname{Der} f 1(\mathrm{ng} / \mathrm{ml})]^{0.91} .
$$

The developed immunoassay system had the dynamic range and precision equivalent to those of ELISA. The results suggested that the system was usable as an alternative

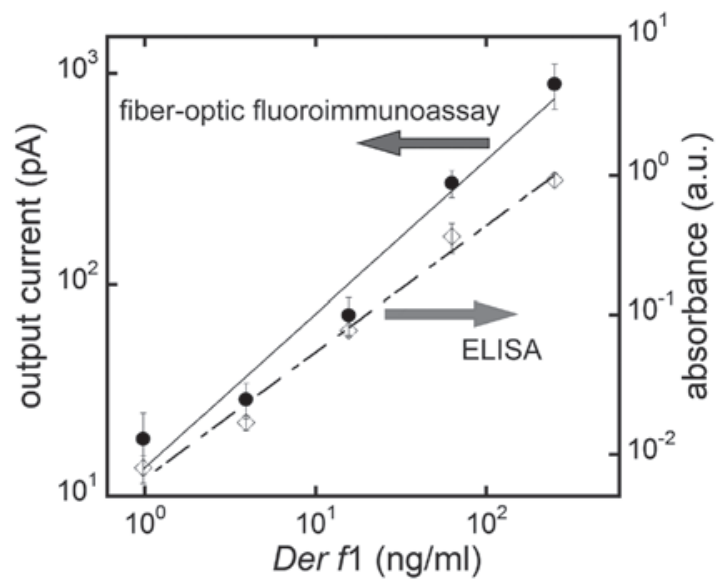

Fig. 5. Calibration curve for Der $f 1$ measured by fluoroimmunoassay. The Der $f 1$ concentration of $250 \mathrm{ng} / \mathrm{ml}$ gave the strongest signal enhancement after secondary antigen-antibody reaction, and the signal strength decreased as the Der $f 1$ concentration decreased. The lower detection limit was $0.98 \mathrm{ng} / \mathrm{ml}$. 
method for the assessment of house dust mite allergen. In addition, the system took at least a tenth of the required time for ELISA. More high-throughput measurement will be available if the fluorescence monitoring of the binding of the detection antibodies and the estimation of the Der $f 1$ concentration are successful.

\subsection{High-throughput measurement by flow system}

After the Cy5-labeled antibody was injected after step III, the change in fluorescent strength was monitored for 5 min. Figure 6 shows the changes in each Der $f 1$ concentration for $30 \mathrm{~s}$ after the labeled antibody was completely injected. After the Cy5labeled antibody was injected, the fluorescence strength was found to increase depending on the concentration of Der $f 1$. In relative terms, the rate of fluorescence increase was faster with increasing $\operatorname{Der} f 1$ concentration.

The changes in fluorescence were analyzed by differential processing, and concentrations of Der $f 1$ were quantified as shown in Fig. 7. The detection range of Der f1 was $0.98-250 \mathrm{ng} / \mathrm{ml}$, and the coefficient of determination was 0.97 as determined by regression analysis as shown by the following equation:

$$
\text { Current slope }(\mathrm{pA} / \mathrm{s})=1.85 \times[\operatorname{Der} f 1(\mathrm{ng} / \mathrm{ml})]^{0.43} \text {. }
$$

The assay was completed within 6 min by monitoring the fluorescence strength in fluorescently labeled antibody binding to antigen forming an immune complex. This is the fastest analysis of Der $f 1$ to the best of our knowledge. The level of house dust mite allergen in a residential environment fluctuates as a result of environmental changes, such as temperature, humidity, or air flow. The immunoassay system can provide the results every $6 \mathrm{~min}$; therefore, the system has potential use in environmental monitoring. For other allergens, in addition, the system will be usable if the appropriate antibody is selected. The study suggests that the self-management for a healthy life and treatment support for allergy are possible using the fiber-optic fluoroimmunoassay system.
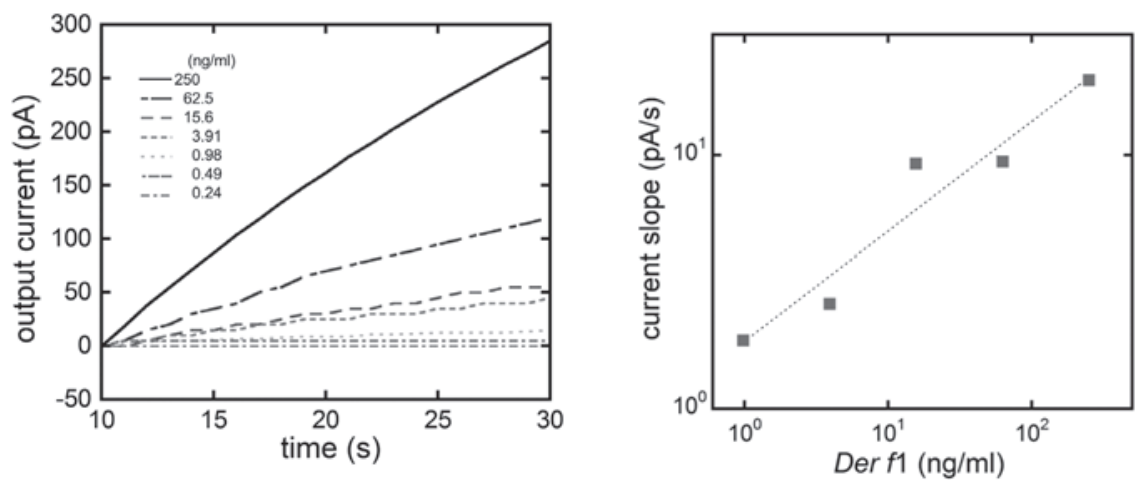

Fig. 6 (left). Fluorescence changes during binding reaction of Cy5-labeled antibody to Der $f 1$ on probe surface.

Fig. 7 (right). Calibration curve for Der $f 1$ quantified by differential processing of changes in fluorescence during labeled antibody binding reaction. The measurement range was from 0.98 to $250 \mathrm{ng} / \mathrm{ml}$. 


\section{Conclusions}

A fiber-optic fluoroimmunoassay system using a flow cell for Der f1 was constructed. $D$. farinae is one of the major components of house dust. In particular, it has been reported that the protein containing their deposits and shells causes allergy such as bronchial asthma and allergic rhinitis. Therefore, rapid and sensitive methods are required to detect these allergenic substances. In this study, we constructed a fiber-optic fluoroimmunoassay system using a flow cell for Der $f 1$ detection. The preparation for the probe and measurement system avoided complicated procedures. The measurement range for Der $f 1$ diluted with PBT was from 0.24 to $250 \mathrm{ng} / \mathrm{ml}$. The system was designed to perform every assay within about $16 \mathrm{~min}$. The detection limit was equal to that of ELISA, which is able to quantify Der $f 1$ with high sensitivity. Moreover, for the implementation of a high-throughput assay, the fluorescence strength was monitored during the binding of a fluorescently labeled antibody to the analyte. The measurement range for quantifying the $\operatorname{Der} f 1$ concentration by differential processing was from 0.98 to $250 \mathrm{ng} / \mathrm{ml}$. This system can potentially be adopted for the detection of other antigens causing allergic diseases. The fiber-optic fluoroimmunoassay system could be one of the best methods to meet the need for rapid, sensitive, and simple detection.

\section{Acknowledgements}

This study was supported by the Japan Science and Technology Agency (JST) and Ministry of Education, Culture, Sports, Science and Technology (MEXT), Special Funds for Education and Research "Advanced Research Program in Sensing Biology". The authors would like to thank Canon Chemicals Inc. for providing the fluorometric assay system PU6102 and disposable optical fiber probes.

\section{References}

1 The International Study of Asthma and Allergies in Childhood (ISSAC) Steering Committee: Lancet 351 (1998) 1225.

2 C. Janson, J. Anto, P. Burney, S. Chinn, R. de Marco, J. Heinrich, D. Jarvis, N. Kuenzli, B. Leynaert, C. Luczynska, F. Neukirch, C. Svanes, J. Sunyer and M. Wjst, on behalf of the European Community Respiratory Health Survey II: Eur. Respir. J. 18 (2001) 598.

3 A. Togias: J. Allergy Clin. Immunol. 111 (2003) 1171.

4 J. Bousquet, P. van Cauwenberge and N. Khaltaev: J. Allergy Clin. Immunol. 108 (5 Suppl) (2001) S147.

5 A. E. Tattersfield, A. J. Knox, J. R. Britton and I. P. Hall: Lancet 360 (2002) 1313.

6 T. A. Platts-Mills, D. Vervloet, W. R. Thomas, R. C. Aalberse and M. D. Chapman: J. Allergy Clin. Immunol. 100 (1997) S2.

7 C. D. Earle, E. M. King, A. Tsay, K. Pittman, B. Saric, L. Vailes, R. Godbout, K. G. Oliver and M. D. Chapman: J. Allergy Clin. Immunol. 119 (2007) 428.

8 J. M. Ingram, R. Sporik, G. Rose, R. Honsinger, M. D. Chapman and T. A. Platts-Mills: J. Allergy Clin. Immunol. 96 (1995) 449.

9 S. M. Pollart, T. F. Smith, E. Morris, L. E. Gelber, T. A. E. Platts-Mills and M. D. Chapman: J. Allergy Clin. Immunol. 87 (1991) 505. 
10 E. Ferrari, A. Tsay, P. A. Eggleston, A. Spinsi and M. D. Chapman: J. Allergy Clin. Immunol. 114 (2004) 341.

11 A. Renstrom, P. H. Larsson, P. Malmberg and C. Bayard: J. Allergy Clin. Immunol. 100 (1997) 649.

12 L. Vailes, S. Sridhara, O. Cromwell, B. Weber, M. Breitenbach and M. D. Chapman: J. Allergy Clin. Immunol. 107 (2001) 641.

13 S. J. Arbes, R. D. Cohn, M. Yin, M. L. Muilenberg, H. A. Burge, W. Friedman and D. C. Zeldin: J. Allergy Clin. Immunol. 111 (2003) 408.

14 R. Voorhost, M. J. E. Spieksma-Boezeman and F. T. M. Spieksma: Allerg. Asthma 10 (1964) 329.

15 E. R. Tovey, M. D. Chapman and T. A. Platts-Mills: Nature 289 (1981) 592.

16 X. van der Brempt, E. Haddi, A. Michel-Nguyen, J. P. Fayon, M. Soler, D. Charpin and D. Vervloet: J. Allergy Clin. Immunol. 87 (1991) 130.

17 C. M. Luczynska, L. K. Arruda, T. A. E. Platts-Mills, J. D. Miller, M. Lopez and M. D. Chapman: J. Immunol. Meth. 118 (1989) 227.

18 M. Sakaguchi: Allergol. Int. 54 (2005) 35.

19 A. G. Mignani, R. Falciai and L. Ciaccheri: Appl. Spectrosc. 52 (1998) 546.

20 J. M. Song, P. M. Kasili, G. D. Griffin and T. Vo-Dinh: Anal. Chem. 76 (2004) 2591.

21 D. W. Kim, Y. Zhang, K. L. Cooper and A. Wang: Electron. Lett. 42 (2006) 324.

22 S. Ko and S. A. Grant: Biosens. Bioelectron. 21 (2006) 1283.

23 J. Waswa, J. Irudayaraj and C. DebRoy: LWT 40 (2007) 187.

24 R. S. Marks, E. Bassis, A. Bychenko and M. M. Levine: Opt. Eng. 36 (1997) 3258.

25 A. Petrosova, T. Konry, S. Cosnier, I. Trakht, J. Lutwama, E. Rwaguma, A. Chepurnov, E. Muhlberger, L. Lovel and R. S. Marks: Sens. Actuators, B 122 (2007) 578.

26 A. Sobarzo, J. T. Paweska, S. Hermann, T. Amir, R. S. Marks and L. Lobel: J. Virol. Methods 146 (2007) 327.

27 W. Jin, G. Stewart and B. Culshaw: Sens. Actuators, B 38 (1997) 42.

28 R. B. Mujumdar, L. A. Ernst, S. R. Mujumdar, C. J. Lewis and A. S. Waggoner: Bioconjugate Chem. 4 (1993) 105.

29 P. L. Southwick, L. A. Ernst, E. W. Tauriello, S. R. Parker, R. B. Mujumdar, S. R. Mujumdar, H. A. Clever and A. S. Waggoner: Cytometry 11 (1990) 418.

30 K. Miyajima, G. Itabashi, T. Koshida, K. Tamari, D. Takahashi, T. Arakawa, H. Kudo, H. Saito, K. Yano, K. Shiba and K. Mitsubayashi: Environ. Monit. Assess. 182 (2011) 233. 